EPiC Series in Engineering
Volume 3, 2018, Pages 70-78
HIC 2018. 13th International
Conference on Hydroinformatics

\title{
Assessment of Irrigation Water Use patterns using remote sensing data in Mexico's northeast
}

\author{
Saúl Arciniega-Esparza ${ }^{1,2}$, José A. Breña-Naranjo², Adrián Pedrozo-Acuña ${ }^{2}$ \\ and Antonio Hernández-Espriú ${ }^{3}$ \\ ${ }^{1}$ Programa de Maestría y Doctorado en Ingeniería, Universidad Nacional Autónoma de México, \\ Mexico City, Mexico \\ ${ }^{2}$ Universidad Nacional Autónoma de México, Instituto de Ingeniería, Mexico City, Mexico \\ ${ }^{3}$ Universidad Nacional Autónoma de México, Facultad de Ingeniería, Mexico City, Mexico \\ sarciniegae@ii.unam.com, jbrenan@ii.unam.com, \\ apedrozoa@ii.unam.com, ahespriu@unam.mx
}

\begin{abstract}
Irrigation water use (IWU) or withdrawal is a key component for the water management of a region since it tends to exceed the crops consumptive water use, especially in water-stressed regions where groundwater is the main source of water. Nevertheless, temporal IWU information is missing in many irrigation areas. Remote sensing (RS) data is commonly used for crop water requirements estimations in areas with lack of data, however, IWU is more complex to approach since it also depends on water use efficiency, irrigation system type, irrigation scheduling, and water availability, among others. This work explores the use of remote sensing data (TRMM, MODIS) and land surface hydrological products (GLDAS 2 and MERRA 2) to obtain insights about the space-time annual IWU patterns across croplands located within Mexico's northeast region. Reported IWU in three irrigation districts (Don Martín, Región Lagunera and Bajo Río Bravo) was used to obtain a functional model using satellite data derived. Results suggest strong relationship between reported IWU with soil moisture content from GLDAS and the maximum annual EVI from MODIS, where a potential regression shown statistical correlations of 0.83 and 0.77 , respectively.
\end{abstract}

\section{Introduction}

Evapotranspiration (ET) is one of the most important components of the hydrological cycle and one of the most complex variables to assess since it depends of meteorological data, soil information, and plant water stress conditions, among others [1]. Nevertheless, for water manager purposes irrigation water use (IWU) is an essential key since water withdrawals for irrigation demands from surface and groundwater sources tend to be higher that crop water demands, mainly due to significant losses during the irrigation processes [2]. 
IWU is the main driver for quantitative water depletion [2,3] especially in arid and semiarid regions where groundwater is the main water supply source [4]. But the lack of measurements and its epidemic uncertainty remains a major constraint to improve strategies related with water use optimization and drought resilience. In order to achieve accurate estimations in large regions, satellite-based data have been widely used to estimates crops water requirement [5-9], however, quantifying groundwater and surface withdrawals for irrigation is even more difficult due to the lack of sufficient information about the space-time irrigation practices [4].

In Mexico, IWU time series are available only for irrigation districts, meanwhile water use in smaller croplands that comprises important water withdrawals is not reported. This work explores the use of available remote sensing data, land surface model products and global map of irrigation areas to obtain insights about the space-time IWU patterns across a set of irrigated areas located across Mexico's northeast region and to attribute such use to groundwater pumping. Observed IWU in three irrigation districts was used to evaluate the climate, soil and vegetation properties that describe the annual variation in water use through a regression model, while irrigation areas attributes from the FAO AQUASTAT database [10] were employed to generate temporal maps of irrigation groundwater use (IWUgw) in the region. Methodology proposed in this study was formulated using free and global databases, and thus can be applied in other regions with minimum irrigation withdrawals information.

\section{Study area description}

The study area (pink polygon in Figure 1.a) comprises a fraction of the hydrological region BravoConchos located in Coahuila and Nuevo Leon states, Mexico. This region suffers a significant rainfall gradient that varies from $150 \mathrm{~mm}$ in the northwest, to $1100 \mathrm{~mm}$ per year in the southeast. The climatology is mainly arid with an aridity index (ratio of annual potential evaporation to annual precipitation) between 3 to 5 . Watersheds are mainly composed of shrublands and deciduous trees, with some important cropland areas (yellow colored, Figure 1.b) mainly located across the east. Croplands (green areas in Figure 1.a) represents the $\sim 6.67 \%$ of the total interest area, where sorghum represents the most abundant crop with $\sim 18.8 \%$ of the total cropland surface, followed by grass $(\sim 13.9 \%)$, orange trees $(\sim 8.7 \%)$, forage $(\sim 7.8 \%)$, corn $(\sim 8.7 \%)$, wheat $(\sim 5.7 \%)$, among others. The Public Repository of Water Rights (REPDA) from the Mexican water commission, CONAGUA, reported an allocated groundwater volume of $1020 \mathrm{hm}^{3}$, which about $72 \%$ corresponds to irrigation and $15 \%$ to urban use.

Some irrigation districts are located across and near the study area (yellow areas in Figure 1.a). Only those that cover a pixel from the lower resolution grids from remote sensing data sources were considered for the space-time statistical analysis: irrigation district 004 "Don Martín", located in the study area; district 017 "Región Lagunera", in Durango-Coahuila states, with an area of $3600 \mathrm{~km}^{2}$; and district 025 "Bajo Río Bravo", in Tamaulipas state, with an area of $2600 \mathrm{~km}^{2}$. 

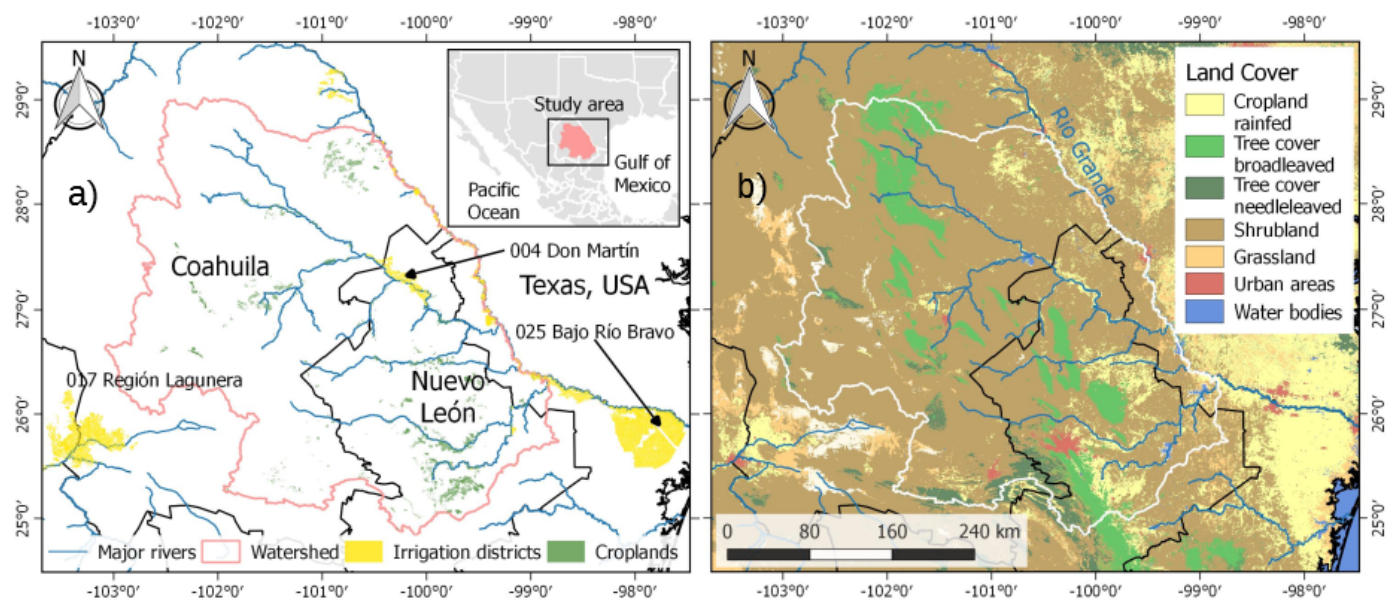

Figure 1: Study area location (a) and land cover derived from ESA CCI [11] (b)

\section{Data and methods}

Data sources and variables used in this study are shown in Table 1. Vegetation indexes (NDVI and EVI) where obtained from MODIS product MOD13Q1 at $250 \mathrm{~m}$ [12]. Climatologic and meteorological variables were extracted from TRMM 3B43 [13], GLDAS 2 [14], MERRA 2 [15], Livneh et al. climatology interpolation from ground gauges and output results from VIC model [16,17], ET and PET were obtained from MODIS MYD16A2 [18]. IWU at annual scale reported for the irrigation districts listed before were consulted in the irrigation districts statistics web page of Mexican Water Technology Institute (IMTA) and CONAGUA (http://www.edistritos.com/DR/) for the period 2002-2015. Annual land cover maps from the Climate Change Initiative (CCI) of the European Space Agency (ESA) with a resolution of $300 \mathrm{~m}$ were used to identify croplands pixels. Finally, global maps of irrigation areas from FAO AQUASTAT [10] were used to obtain the percentage of area equipped for irrigation as well as the percentage of area irrigated with groundwater and surface water.

\begin{tabular}{|c|c|c|c|}
\hline Type & Variable & Description & Sources \\
\hline \multirow{6}{*}{ 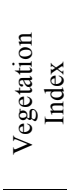 } & NDVImean & Mean annual Normalized Difference Vegetation Index & MODIS \\
\hline & NDVImax & Maximum annual NDVI & MODIS \\
\hline & NDVIsum & Annual cumulative NDVI & MODIS \\
\hline & EVImean & Mean annual Enhanced Vegetation Index & MODIS \\
\hline & EVImax & Maximum annual EVI & MODIS \\
\hline & EVIsum & Annual cumulative EVI & MODIS \\
\hline \multirow{9}{*}{ 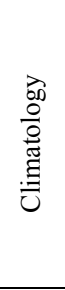 } & Prec & Precipitation & TRMM, GLDAS 2, MERRA 2, Livneh \\
\hline & ET & Actual evapotranspiration & GLDAS 2, MERRA 2, Livheh, MODIS \\
\hline & PET & Potential evapotranspiration & GLDAS 2, MERRA 2, Livheh, MODIS \\
\hline & SM & Soil moisture & GLDAS 2, MERRA 2, Livheh \\
\hline & SMC & Soil moisture content & GLDAS 2, MERRA 2, Livheh \\
\hline & Tmed & Mean temperature & Livneh \\
\hline & Prec-ET & Semi-balance approach & Derived from sources listed \\
\hline & EI & Evaporative Index (ET/Prec) & Derived from sources listed \\
\hline & AI & Aridity Index (PET/Prec) & Derived from sources listed \\
\hline \multirow{3}{*}{\multicolumn{2}{|c|}{ 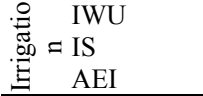 }} & Irrigation Water Use & IMTA and CONAGUA \\
\hline & & Irrigated surface & IMTA and CONAGUA \\
\hline & & Percentage of total area equipped for irrigation & FAO Global Map of Irrigation Areas v5 \\
\hline
\end{tabular}




\begin{tabular}{cl}
\hline AEIGW & $\begin{array}{l}\text { Area irrigated with groundwater expressed as percentage FAO Global Map of Irrigation Areas v5 } \\
\text { of total area equipped for irrigation } \\
\text { Area irrigated with surface water expressed as percentage } \\
\text { of total area equipped for irrigation }\end{array}$ \\
\hline
\end{tabular}

Table 1: Variables description used in this study

Proposed methodology is shown in Figure 2. In summary, is expected that space-time series of reported IWU can be explained by climatologic variables, vegetation health and global information of irrigation areas, assuming irrigation technology and water use efficiency similar across the area.

\section{Results and discussions}

Irrigation water requirement can be estimated using information about the crops demands, effective precipitation and changes in soil moisture [2], thus, following the assumptions in the methodology, IWU is proportional to the climate and vegetation conditions. This hypothesis is analyzed in Figure 3 a) and c), where semi water balance approach shown that as water deficit increases, water withdrawals for irrigation increases in a proportional ratio.

Climatologic and vegetation annual series (considering agricultural year) are compared with IWU series in Figure $3 \mathrm{~d}$ ), e) and f). Mean annual IWU have been reported as 1600, 1621 and $424 \mathrm{~mm} /$ year for the districts 004, 017 and 025, respectively. Furthermore, precipitation and evapotranspiration represent the $30 \%$ of the IWU in district 004 and $9-15 \%$ in district 017 , but for district 025 , Prec and ET are higher in a $40 \%$. Mean annual SMC varies from 0.16 to $23 \%$ across the districts, meanwhile mean annual NDVI and EVI ranges between $0.24-0.36$ and $0.19-0.24$, respectively.

IWU presented a negative correlation with precipitation from TRMM $(\rho=-0.68)$, soil moisture content from GLDAS $(\rho=-0.88)$ and evapotranspiration from GLDAS $(\rho=-0.84)$, moreover, mean annual NDVI is not directly associated to water withdrawals, but maximum annual EVI manifested an inverse strong relationship $(\rho=-0.87)$. 


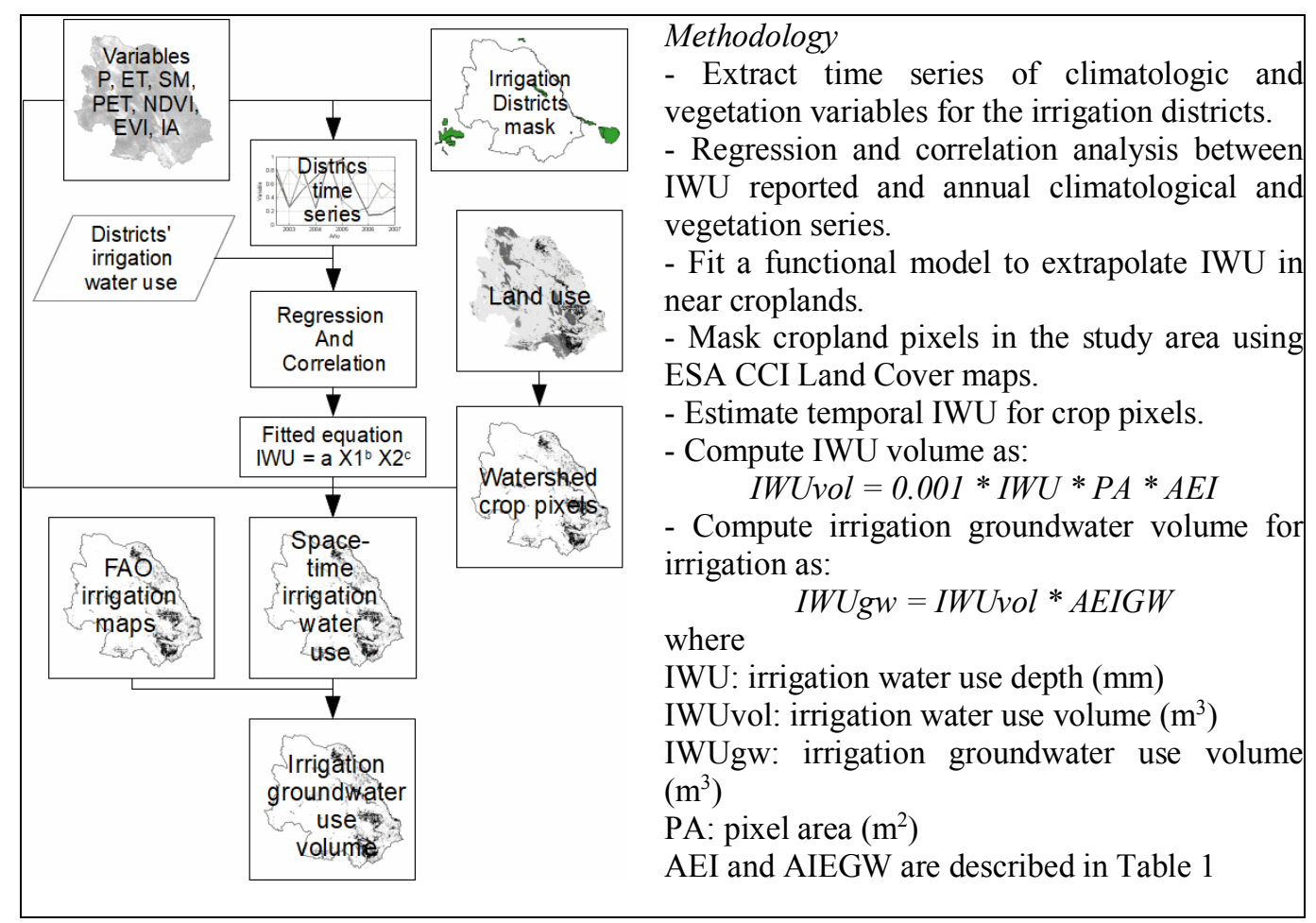

Figure 2: Proposed methodology scheme and steps for space-time IWU analysis
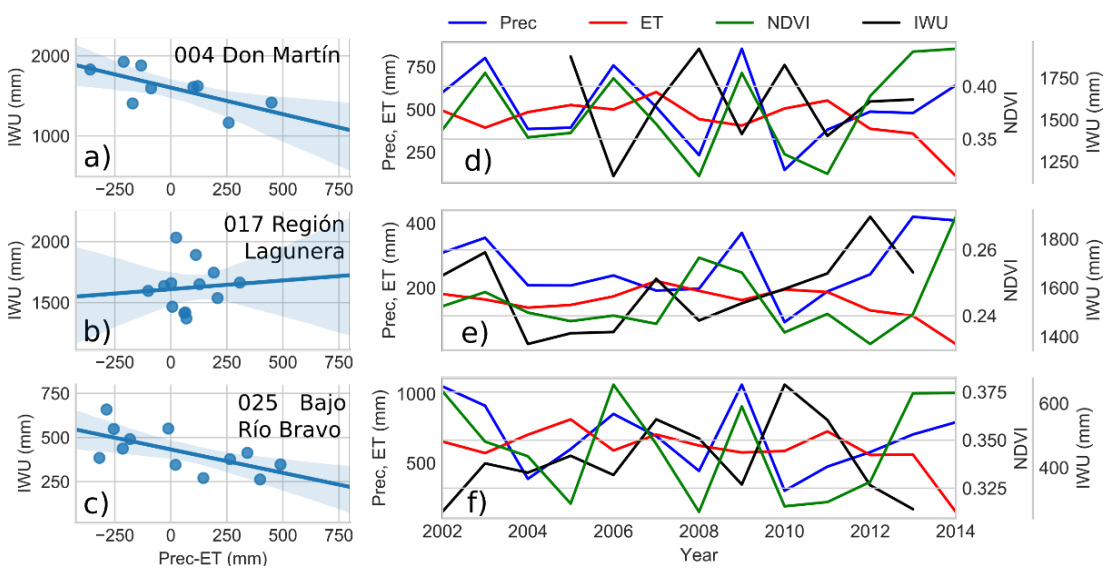

Figure 3: Correlation between semi water balance and IWU for the irrigation districts ( $a, b$ and $c)$ and annual time series of the main water balance components (d, e and f). Prec from TRMM, ET and NDVI from MODIS, and IWU from IMTA database

Multiple regressions models were tested considering 1 to 3 variables. For models with more than one variable, correlation and determination coefficient were poorly improved $(5-10 \%$ increase in correlation), thus, a model with a single variable was preferred. Results suggest that in all irrigation districts, soil moisture content variations (SMC) from GLDAS 2 and the maximum annual enhanced vegetation index (EVI) from MODIS are key controlling variables that exhibit a good correlation ( 0.83 and 0.77 , respectively) with respect to observed IWU, as showed in Table 2. 


\begin{tabular}{lllllll}
\hline Eq & Model & Elements & r2 & RSMD $(\mathrm{mm})$ & $\rho$ & $\mathrm{p}$-value \\
\hline 1 & $I W U=0.2404 S M C_{G L D A S}^{-4.908}$ & 22 & 0.81 & 84.83 & 0.83 & $>0.0001$ \\
2 & $I W U=55.7343 E V I_{\max }^{-2.4809}$ & 34 & 0.63 & 78.83 & 0.77 & $>0.0001$ \\
\hline
\end{tabular}

Table 2: Variables description used in this study

Fitted models are presented in Figure 4, where a) shows the scatterplot of observed IWU in three districts against the estimation using equations 1 and 2. Estimated determination coefficient is higher for eq. 1 ( 0.81 against 0.63$)$, but number of elements were lower since GLDAS 2 data is available until 2009, leaving an important period without information (2010-2015). Temporal variation of estimated and reported IWU for each irrigation district is showed in Figure 4 b), c) and d). Better performance using eq. 2 was carried in districts 017 and 025 according to RSMD (128 and $49 \mathrm{~mm}$, respectively), besides, district 004 presented a substantial error of $222.6 \mathrm{~mm}$. In the other hand, eq. 1 provides a better correlation with reported IWU $(0.63,0.72$ and 0.55$)$.

Since EVI $_{\max }$ is highly related with SMCGLDAS $(\rho=0.89)$, both variables explain the increase of water use for irrigation during drought periods. In such cases, given the rapid depletion of soil moisture, more water is required for irrigation, while high soil moisture conditions during periods of relative high wetness are associated with natural conditions for larger crop production (high EVI values).
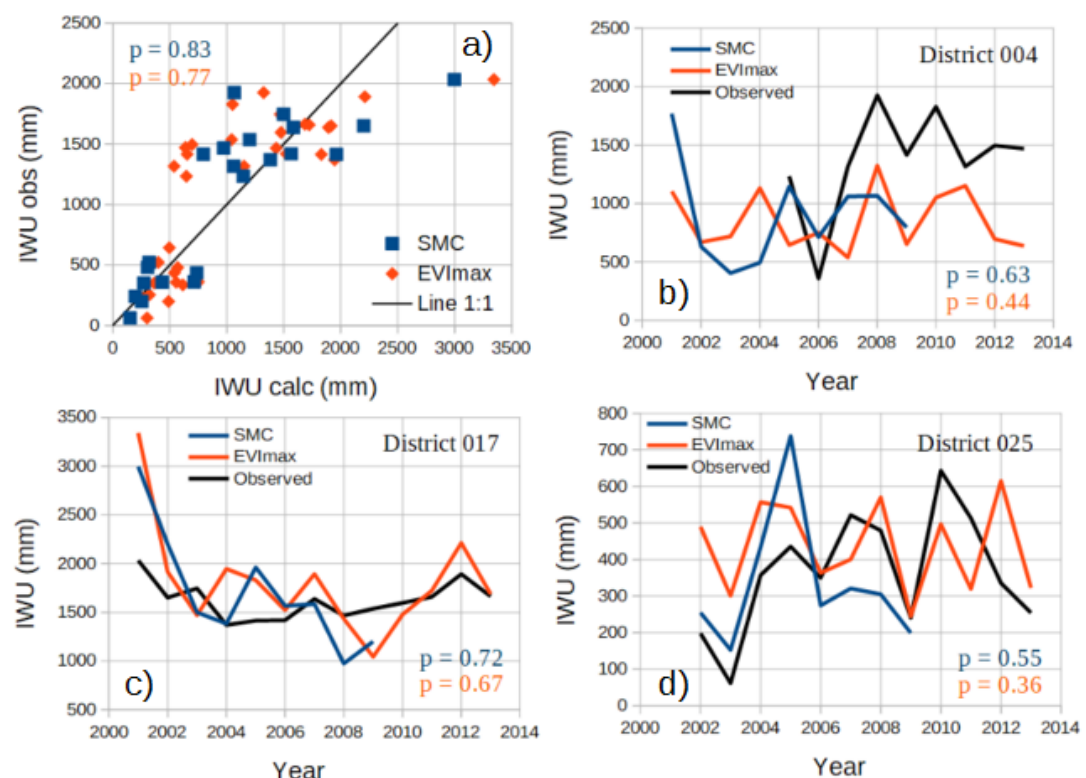

Figure 4: Comparison of annual IWU derived from $\mathrm{SMC}_{\mathrm{GLDAS}}, \mathrm{EVI}_{\max }$ and reported for a) the three irrigation districts, b) district 004 "San Martín", c) district 017 "Región Lagunera" and d) district 025 "Bajo Río Bravo"

Annual IWU volume was calculated following the methodology exposed in Figure 2. For validate volume estimations in croplands across the study area, irrigated area ratio (irrigated area/total area) for each irrigation district were compared with AIE obtained from FAO maps (see Table 1). Mean annual irrigated area ratio for district 004 is reported as 0.29 and applying a spatial average was estimated as 0.24 from FAO. For district 017 these values are 0.20 and 0.27 , and for district 025 correspond to 0.77 and 0.82 . It must be noted that irrigated area ratio from IMTA database remains almost constant over time and average comparison is valid, but for poor equipped irrigation areas where crops' growth is larger dependent of natural water availability, irrigation area ratio could vary 
strongly, leading an important error source. Results for irrigation districts 017 and 025 were consistent with observed volumes, nevertheless for district 004, estimated IWU volume was underestimated.

Spate-time variation of IWU across study area was calculated with eqs. 1 and 2, but only results using SMC are showed in Figure 5. Mean annual IWU using a time-spatial average was estimated as 817.4 and $664.2 \mathrm{~mm} / \mathrm{year}$ for $\mathrm{SMC}_{\mathrm{GLDAS}}$ and $\mathrm{EVI}_{\max }$ for common period (2001-2008), whereas standard deviation was estimated as 438.8 and $491.7 \mathrm{~mm}$, respectively. According to results, from 2003 to 2008 IWU increased in whole area from 390 to $675 \mathrm{~mm}$ (Figure $5 \mathrm{a}$ and b), meanwhile peak water withdrawals of $1330.9 \mathrm{~mm}$ was estimated in 2011 using eq. 2 (Figure 6) when an exceptional drought affected USA and northern regions of Mexico [19].

Spatial distribution of irrigation groundwater withdrawals for 2003 and 2008 are shown in Figure 5 b) and d), and temporal variation for period 1993-2014 is presented in Figure 6 b). According to FAO maps, in the study area $8.1 \%$ of the croplands are equipped for irrigation, meanwhile only $55 \%$ of equipped areas use groundwater as water source. Intensive irrigated areas with groundwater are appreciated in red in Figure $5 \mathrm{~d}$ ), that corresponds to croplands in the Allende-Piedras Negras aquifer at the north which are mainly irrigated with regional groundwater from springs [20]. Other intensive areas are observed at the west and east of the study area, meanwhile blue regions correspond to rainfed and surface water irrigated areas.

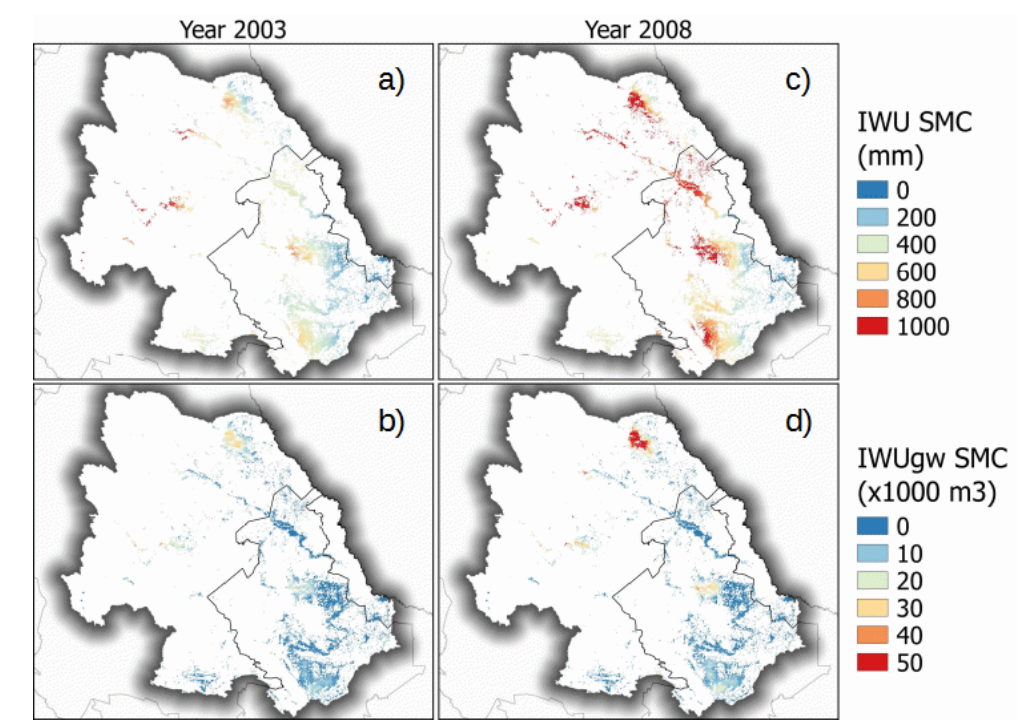

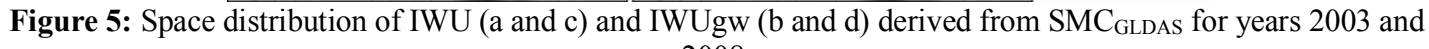
2008.

Temporal IWUgw series were compared with groundwater volume concessions from REPDA (black dashed line) in Figure 6. Mean annual IWUgw for the common period is half of the volume reported in REPDA (382 $\mathrm{hm}^{3}$ estimated against $737 \mathrm{hm}^{3}$ reported) using eqs. 1 and 2, nevertheless mean annual long term IWUgw using SMC as estimator is $605 \mathrm{hm}^{3}$ (estimated) and $810 \mathrm{hm}^{3}$ (reported) considering period 1993-2002.

Despite the poor fit with respect reported groundwater withdrawals in the area, fitted models reproduced annual patterns of the water withdrawals in the irrigation districts, leading information about the farmers irrigation practices. Differences between estimations and volume concessions are derived from the lack measurements in irrigated areas and since water users are not obligated to report withdrawals, thus temporal withdrawals variations are not available and REPDA volumes represents a static in time reference of the human water stress induced in the area. 


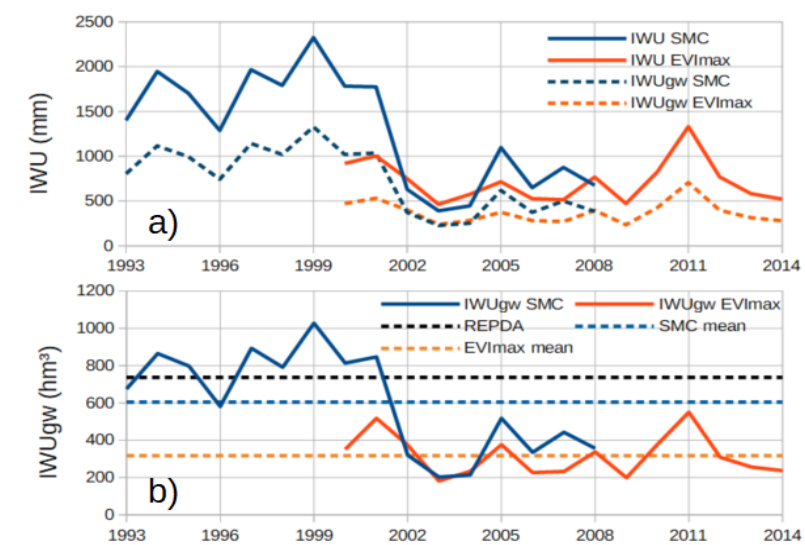

Figure 6: Temporal patterns of a) IWU and b) IWUgw in the study area for the period 1993-2014

\section{Conclusions}

A methodology was proposed to assess the space-time dynamics of irrigation water use in a semiarid region located in Mexico's northeast. Annual observed IWU from three irrigation districts with similar crops were used to calibrate a regression equation that included several hydrological variables and vegetation indexes derived from land surface models and remote sensing databases. Soil moisture content from GLDAS 2 and maximum annual EVI from MODIS were found to be the main drivers of water use for irrigation.

Furthermore, maps of irrigated areas from the FAO global irrigation database were used to generate annual maps of groundwater use for irrigation purposes to identify intensive irrigation areas. Results suggest that groundwater withdrawals are the half of reported concession volumes, but the lack of available data to calibrate the models leads an important uncertainty source.

As shown above, fitted models explains the effect of wet and dry years in water resources since deficit water periods are related with increases in water withdrawals, thus, temporal water stress in the region could be more properly analyzed.

Proposed methodology can be improved to infer water use at higher resolutions $(<300 \mathrm{~m})$, but more variables (crop type, crops intensity, soil moisture measurements, water use efficiency) are necessary to perform such analysis.

\section{References}

[1] R. G. Allen, L. S. Pereira, D. Raes, M. Smith, Crop evapotranspiration - Guidelines for computing crop water requirements - FAO Irrigation and drainage paper 56. Irrig. Drain. (1998) 1-15, doi:10.1016/j.eja.2010.12.001.

[2] K. Frenken, V. Gillet, Irrigation water requirement and water withdrawal by country, 2012.

[3] S. Siebert, P. Döll, Irrigation water use - A global perspective. Glob. Chang. Enough Water all? 25 (2007) 104-107, doi:10.1029/2001WR000355.D.

[4] S. Siebert, J. Burke, J. M. Faures, K. Frenken, J. Hoogeveen, P. Döll, F. T. Portmann, Groundwater use for irrigation - A global inventory. Hydrol. Earth Syst. Sci. 14 (2010) 18631880, doi:10.5194/hess-14-1863-2010.

[5] M. A. Bashir, T. Hata, H. Tanakamaru, A. W. Abdelhadi, A. Tada, Remote sensing derived crop 
coefficient for estimating crop water requirements for irrigated sorghum in the Gezira scheme, Sudan. J. Environ. Informatics 10 (2007) 47-54, doi:10.3808/jei.200700099.

[6] A. Calera; I. Campos, A. Osann, G. D’Urso, M. Menenti, Remote sensing for crop water management: From ET modelling to services for the end users. Sensors (Switzerland) 17 (2017) 1-25, doi:10.3390/s17051104.

[7] E. Farg, S. M. Arafat, M. S. Abd El-Wahed, A. M. El-Gindy, Estimation of Evapotranspiration ETc and Crop Coefficient Kc of Wheat, in south Nile Delta of Egypt Using integrated FAO-56 approach and remote sensing data. Egypt. J. Remote Sens. Sp. Sci. 15 (2012) 83-89, doi:10.1016/j.ejrs.2012.02.001.

[8] J. E. Hunink, S. Contreras, M. Soto-García, B. Martin-Gorriz, V. Martinez-Álvarez, A. Baille, Estimating groundwater use patterns of perennial and seasonal crops in a Mediterranean irrigation scheme, using remote sensing. Agric. Water Manag. 162 (2015) 47-56, doi:10.1016/j.agwat.2015.08.003.

[9] H. Li, L. Zheng, Y. Lei, C. Li, Z. Liu, S. Zhang, Estimation of water consumption and crop water productivity of winter wheat in North China Plain using remote sensing technology. Agric. Water Manag. 95 (2008) 1271-1278, doi:10.1016/j.agwat.2008.05.003.

[10] S. Siebert, P. Döll, S. Feick, K. Frenken, J. Hoogeveen, Global Map of Irrigation Areas version 5. Univ. Frankfurt (Main), Ger. FAO, Rome, Italy. (2013) 1-2, doi:10.13140/2.1.2660.6728.

[11] S. Bontemps, P. Defourny, C. Brockmann, M. Herold, V. Kalogirou, O. Arino, New global land cover mapping exercise in the framework of the ESA Climate Change Initiative. In International Geoscience and Remote Sensing Symposium (IGARSS) (2012) 4447.

[12] K. Didan, MOD13Q1 - MODIS/Terra Vegetation Indices 16-Day L3 Global 250m SIN Grid. NASA EOSDIS LP DAAC (2015) doi: 10.5067/MODIS/MOD13Q1.006.

[13] G. J. Huffman, R. F. Adler, D. T. Bolvin, E. J Nelkin, The TRMM Multi-satellite Precipitation Analysis (TMPA). In Satellite Rainfall Applications for Surface Hydrology (2010) 3-22 ISBN 9789048129140.

[14] R. Hualan, B. Hiroko, Global Land Data Assimilation System Version 2 (GLDAS-2) Products 2 (2013).

[15] M. G. Bosilovich, F. R. Robertson, L. Takacs, A. Molod, D. Mocko, Atmospheric Water Balance and Variability in the MERRA-2 Reanalysis. J. Clim. (2016), doi:10.1175/jcli-d-16-0338.1.

[16] B. Livneh, D. S. Pierce, T. J. Bohn, F. Munoz-Ariola, B. Nijssen, D. Cayan, R. Vose, L. D. Brekki, Development of a spatially comprehensive, daily hydrometeorological data set for Mexico, the conterminous U.S., and southern Canada: 1950-2013. Nat. Sci. Data 2 (2015) 150042.

[17] B. Livneh, E. A. Rosenberg, C. Lin, B. Nijssen, V. Mishra, K. M. Andeadis, E. P. Maurer, Lettenmaier, D. P. A long-term hydrologically based dataset of land surface fluxes and states for the conterminous United States: Update and extentions. J. Clim. 26 (2013) 9384-9392, doi:10.1175/JCLI-D-12-00508.1.

[18] Q. Mu, M. Zhao, S. W. Running, Improvements to a MODIS global terrestrial evapotranspiration algorithm. Remote Sens. Environ. 115 (2011) 1781-1800, doi:10.1016/j.rse.2011.02.019.

[19] B. R. Scanlon, I. Duncan, R. C. Reedy, Drought and the water-energy nexus in Texas. Environ. Res. Lett. 8 (2013) 45033, doi:10.1088/1748-9326/8/4/045033.

[20] CONAGUA Actualización de la disponibilidad media anual de agua en el acuífero AllendePiedras Negras (0501), Estado de Coahuila 2014 